\title{
THE SUPRASCAPULAR NOTCH: ITS MORPHOLOGY MORPHOM- ETRY AND CLINICAL SIGNIFICANCE
}

\author{
M Venkata Raga Mayuri ${ }^{1}$, T Naveen Sagar *2. \\ ${ }^{1}$ Assistant professor, Department of Anatomy, Meenakshi Medical College, Kanchipuram, Tamilnadu, \\ India
}

${ }^{{ }^{2}}$ Assistant professor, Department of Anatomy, Apollo Institute of Medical Sciences and Research, Chittoor, Andhra Pradesh, India.

\section{ABSTRACT}

\begin{abstract}
Introduction: The Scapula is a large, flat, triangular bone which lies on the posterolateral aspect of the chest wall. The Suprascapular notch is a depression on the superior border of the scapula which gives passage to Suprascapular nerve. Anatomical variations of the shape and size of notch is useful as it is the common site of Suprascapular nerve entrapment syndrome.

Materials and Methods: The present study was carried out on 60 adult dry human Scapulae. Different shapes of Suprascapular notch was observed, then vertical and transverse dimensions of the notch were measured.

Results and Conclusion: Based on Rengachary classification, type III notch was found to be most common. Suprascapular foramen was observed in 5 Scapulae. The mean vertical and transverse diameters were measured as $6.43 \mathrm{~mm}$ and $9.81 \mathrm{~mm}$ respectively. The study of morphology and morphometry of Suprascapular notch helps to correlate Suprascapular nerve entrapment with specific type of notch.
\end{abstract}

KEY WORDS: Suprascapular notch, Suprascapular foramen, Suprascapular nerve entrapment.

Corresponding Author: Dr T Naveen Sagar, Assistant professor, Department of Anatomy, Apollo Institute of Medical Sciences and Research, Chittoor, Andhra Pradesh, India. phone: 8106701848 E-Mail: tnsdsmbbs@gmail.com

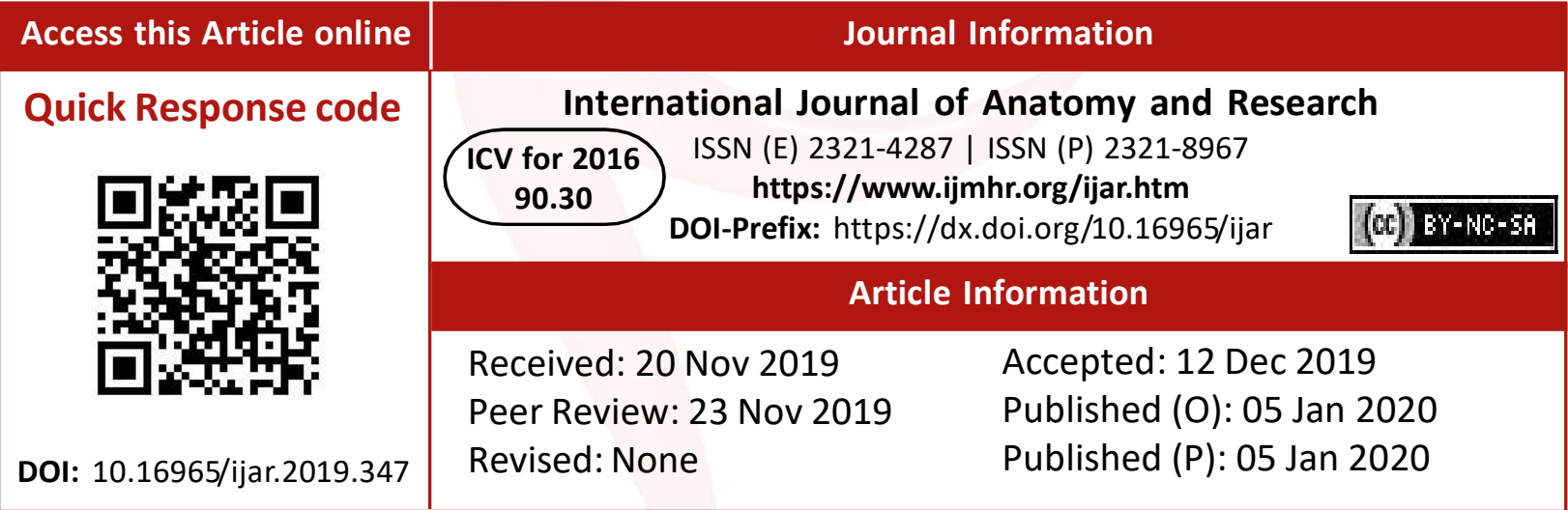

\section{INTRODUCTION}

The scapula is a large, flat, triangular bone which lies on the postero-lateral aspect of the chest wall, covering parts of the second to seventh ribs. It has costal and dorsal surfaces; superior, lateral and medial borders ; inferior, superior and lateral angles, and three processes, the spine, its continuation the acromion and the coracoid process. The superior border, thin and sharp, is the shortest border. At its anterolateral end it is separated from the root of the coracoid process by the suprascapular notch. The notch is bridged by the superior transverse ligament which is attached laterally to the root of the coracoid process and medially to the limit of the notch. The foramen, thus completed, transmits the suprascapular nerve to the supraspinous fossa where it supplies Supraspinatus, winds round spinoglenoid notch to supply Infraspinatus and gives an articular twig to the capsule of shoulder joint. The suprascapular vessels pass backwards above the ligament [1].

Sometimes the ligament is ossified and serves as a bony tunnel for suprascapular nerve. The suprascapular nerve is liable to compression when crossing this bony tunnel. 
In 1936 Andre Thomas, Orthopaedic surgeon was the first to describe suprascapular neuropathy. This syndrome is characterized by pain on the posterolateral aspect of shoulder joint and atrophy of Supraspinatus \& Infraspinatus muscles. Anatomical variations of suprascapular notch are also a possible cause of suprascapular entrapment. Knowing the anatomical variations in detail, along the course of suprascapular nerve, is important for a better understanding of the location and source of entrapment syndrome.

\section{MATERIALS AND METHODS}

The present study was done on 60 adult dry human scapulae of unknown age and sex, obtained from the Department of Anatomy, Sri Venkateswara medical college, Tirupati. Presence or absence of notch was observed and its shape noted. The following morphometric parameters are measured by using digital vernier calipers, accuracy corrected to $0.1 \mathrm{~mm}$-Transverse diameter - maximum horizontal distance between the corners of the notch on the superior border of scapula.

Vertical diameter - maximum vertical distance between the deepest point of the notch to the midpoint on the imaginary plane between the superior corners of the notch.

Distance from the base of suprascapular notch to superior rim of glenoid cavity.

Fig. 1: Measuring the transverse diameter of supra scapular notch.

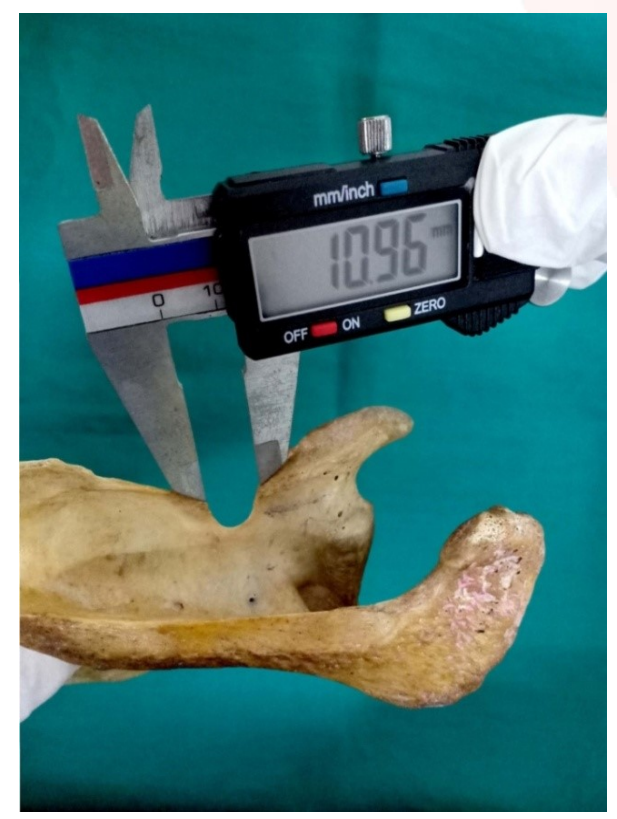

Fig 2: Showing the vertical diameter of supra scapular notch.

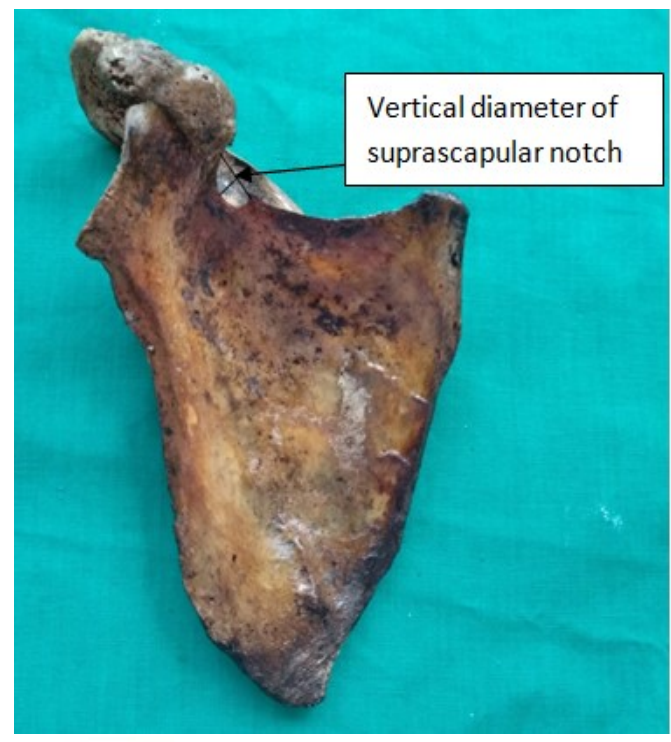

Fig. 3: Different types of supra scapular notch.

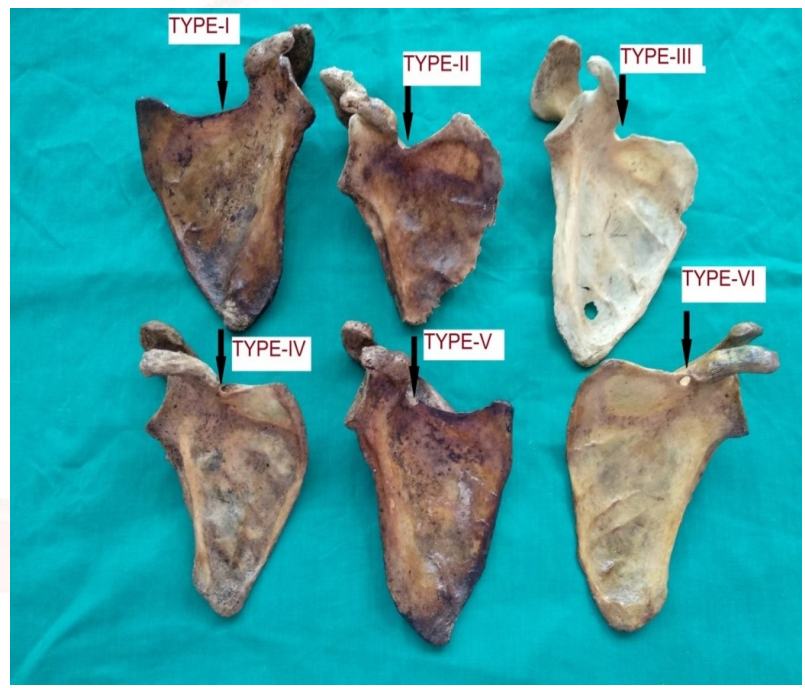

Fig. 4: Scapula with supra scapular foramen.

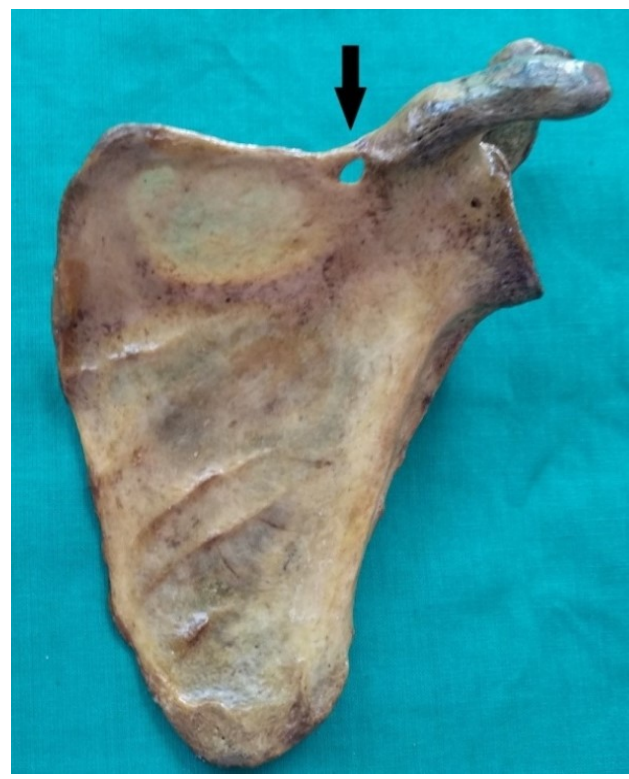




\section{RESULTS}

Table 1: showing distribution of various shapes of suprascapular notch based on Rengachary classification.

\begin{tabular}{|l|c|}
\hline \multicolumn{1}{|c|}{ Shape of the notch } & Percentage(\%) \\
\hline Type I ( No notch) & 10 \\
\hline Type II ( wide, blunt 'V' shaped) & 16.67 \\
\hline Type III ( symmetrical 'U' shaped) & 40 \\
\hline Type IV ( small 'v' shaped) & 21.67 \\
\hline $\begin{array}{l}\text { Type V ( 'U' shaped with medial part of } \\
\text { ligament ossified) }\end{array}$ & 3.33 \\
\hline Type V ( ligament completely ossified) & 8.33 \\
\hline
\end{tabular}

Table I depicts Type III to be the most common type in the present study and Type $V$ was least common.

Table 2: showing the morphometric measurements of suprascapular notch.

\begin{tabular}{|l|c|}
\hline \multicolumn{1}{|c|}{ Parameter } & Mean $(\mathrm{mm})$ \\
\hline Transverse diameter & 9.81 \\
\hline Vertical diameter & 6.43 \\
\hline $\begin{array}{l}\text { Distance from base of suprascapular } \\
\text { notch to superior rim of glenoid. }\end{array}$ & 32.29 \\
\hline
\end{tabular}

In 73.33\% scapulae, transverse diameter is more than vertical diameter and in $8.34 \%$ scapulae vertical diameter is more than transverse diameter.

\section{DISCUSSION}

Shapes of suprascapular notch have been studied in different populations and various classifications were given by different authors. Hrdlicka (1942) [2] was the first to separate suprascapular notches into 5 types. Rengachary et al (1979) [3]., studied on American population and classified scapular notches into six types. Ticker et al (1998). [4], and Bayramoglu et al(2003). [5], modified the classification of Rengachary et al(1979) [3]., and included only three types. Iqbal et al (2010). [6], studied on Islamic population and classified scapular notches into three types, ' $U$ ',' $V$ ','J'.

Rengachary et al [3] classified the notches based on depth, width and the widest point within the notch and explained that small notch have greater chance of nerve impingement. Dulkengrun et al [7] found in his study that ' $V$ ' shaped notches have lesser area than ' $U$ ' shaped notches, and is a causative factor for suprascapular nerve entrapment syndrome. Cummins et al [8] also found that ' $V$ ' shaped suprascapular notch was commonly associated with suprascapular nerve entrapment syndrome. Type $\mathrm{VI}$ (complete ossification of the ligament) scapulae was reported by Silva et al(2007) [9]., Sinkeet et al(2010) [10]., Polguj et al(2011) [11], and Soni et al(2012) [12]., in 30.76\%, 3\%, 7\% and 3\% respectively. Out of 204 scapulae, 2 scapulae with bony foramen inferiorly and notch superiorly was described by Natsis et al(2008) [13].

Natsis et al (2007) [14]. classified suprascapular notch based on vertical and transverse diameter measurements. Type I- without a discrete notch, type II - a notch with the longest transverse diameter, type III - a notch with the longest vertical diameter, type IV - a bony foramen, type $\mathrm{V}-\mathrm{a}$ notch and a foramen.

Table 4: Comparison of frequency of various types of suprascapular notches in different populations based on Natsis [14] classification.

\begin{tabular}{|c|c|c|c|c|}
\hline Type of notch & $\begin{array}{c}\text { Natsis et al [14] } \\
\text { (Greek) }\end{array}$ & $\begin{array}{c}\text { Wang et al. [16] } \\
\text { (Chinese) }\end{array}$ & $\begin{array}{c}\text { Muralidhar et al } \\
\text { [15] (India) }\end{array}$ & $\begin{array}{c}\text { Present } \\
\text { study }\end{array}$ \\
\hline I & $8.30 \%$ & $28 \%$ & $21.25 \%$ & $10 \%$ \\
\hline II & $41.85 \%$ & $56.16 \%$ & $56.73 \%$ & $73.33 \%$ \\
\hline III & $41.85 \%$ & $28.23 \%$ & $14.42 \%$ & $8.34 \%$ \\
\hline IV & $7.30 \%$ & $3 \%$ & $1.92 \%$ & $8.33 \%$ \\
\hline V & $0.70 \%$ & - & - & - \\
\hline
\end{tabular}

Table 3: Comparison of distribution of various types of suprascapular notches in different populations based on Rengachary classification.

\begin{tabular}{|c|c|c|c|c|c|}
\hline $\begin{array}{c}\text { Types of suprascapular } \\
\text { notch }\end{array}$ & $\begin{array}{c}\text { Rengachary et al [3] } \\
\text { (America) }\end{array}$ & $\begin{array}{c}\text { Natsis et al [14] } \\
\text { (Greek) }\end{array}$ & $\begin{array}{c}\text { Sinkeet et al [10] } \\
\text { (Kenya) }\end{array}$ & $\begin{array}{c}\text { Muralidhar et al [15] } \\
\text { (India) }\end{array}$ \\
\hline Type I & $6 \%$ & $8 \%$ & $22 \%$ & $21.15 \%$ \\
\hline Type II & $24 \%$ & $31 \%$ & $21 \%$ & $8.65 \%$ \\
\hline Type III & $40 \%$ & $48 \%$ & $29 \%$ & $59.61 \%$ \\
\hline Type IV & $13 \%$ & $3 \%$ & $5 \%$ & $2.88 \%$ \\
\hline Type V & $11 \%$ & $6 \%$ & $18 \%$ & $21.67 \%$ \\
\hline Type VI & $6 \%$ & $4 \%$ & $4 \%$ & $3.76 \%$ \\
\hline
\end{tabular}


Soni et al (2012). [12], stated that in $72 \%$ of scapulae transverse diameter is more than vertical diameter and in $20 \%$ scapulae vertical diameter is more than transverse diameter. In the study done by Apurba Patra et al. [17], in 67.34\% scapulae transverse diameter of the notches is more than vertical diameter and in $14.28 \%$ vertical diameter was more than transverse diameter. The size of the suprascapular notch is considered to play a part in the predisposition for nerve entrapment. A smaller suprascapular notch hasmore more chances of suprascapular nerve entrapment more than a larger notch.

\section{CONCLUSION}

Anatomical variations of the shape and size of suprascapular notch is useful as the notch is the common site of nerve compression leading to suprascapular nerve entrapment syndrome. The shape of the notch alter the distance between it and the supraglenoid tubercle, which is important for the determination of a potential safe zone to minimize the risk of iatrogenic injury of the suprascapular nerve during arthroscopic procedures and other open procedures requiring dissection of the posterior glenoid neck.

\section{ACKNOWLEDGEMENTS}

Authors are expressing their gratitudes to, Prof. and Head, Department of Anatomy, Sri Venkateswara medical college, Tirupati, for granting the permission to carry out the research.

\section{Conflicts of Interests: None}

\section{REFERENCES}

[1]. Standring S. Gray's Anatomy, 40th Ed, Elsevier Churchill Livingstone, London,2008; P: 793-96.

[2]. Hrdlicka A. The scapula: Visual observations. Am J Phys Anthropol 1942; 29: 73-94.

[3]. Rengachary SS, Burr D, Lucas S, Hassanein KM, Mohn MP, Matzke H. Suprascapular entrapment neuropathy: A clinical, anatomical, and comparative study. Part 2: anatomical study. Neurosurgery 1979; 5: 447-51.

[4]. Ticker JB, Djurasovic M, Strauch RJ, April EW, Pollock RG, Flatow EL, Bigliani LU. The incidence of ganglion cysts and other variations in anatomy along the course of the suprascapular nerve. J Shoulder Elbow Surg 1998; 7:472-8.
[5]. Bayramoglu A, Demiryurek D, Tuccar E, Erbil M, Aldur MM, Tetik O, Doral MN. Variations in anatomy at the suprascapular notch possibly causing suprascapularnerve entrapment: An anatomical study. Knee Surg Sports Traumatol Arthroscopy, 2003; 11: 393-8.

[6]. Iqbal K, Iqbal R, Khan SG. Anatomical variations in shape of suprascapular notch of scapula. J Morphol Sci. 2010; 27:1-2.

[7]. Dunkelgrun M, Lesaka K, Park SS, Kummer FJ, Zuckkerman JD. Interobserver reliability and intraobserver reproducibility in suprascapular notch typing. Bull Hosp Joint Dis.2003; 61: 118-22.

[8]. Cummins CA, Anderson K, Bown M, Nuber G, Roth SI. Anatomy and histological characteristics of the spinoglenoid ligament. J Bone Joint Surg Am. 1998; 80:1622-1625.

[9]. Silva JG. High Incidence of Complete Ossification of the Superior Transverse Scapular Ligament in Brazilians and its Clinical Implications. Int. J. Morphol., 2007; 25(4):855-59.

[10].Sinkeet SR, Awori KO, Odula PO, Ogeng'o JA, Mwachaka PM. The suprascapular notch: its morphology and distance from the glenoid cavity in a Kenyan population; Folia Morphol, 2010; 69(4):24145.

[11]. Polguj M, Jêdrzejewski KS, Podgórski M, Topol M: Correlation between morphometry of the suprascapular notch and anthropometric measurements of the scapula. Folia Morphol 2011; 70: 109-115.

[12]. Malik G, Soni VS, Shukla L, Chabbra S, Gaur N. Morphometric Analysis of the Suprascapular Notch. The Internet Journal of Biological Anthropology. 2012;5(1). DOI:10.5580/2B19.

[13]. Natsis K. A bony bridge within the suprascapular notch. Anatomic study and clinical relevance-Case report. Aristotle University Medical Journal, 2008; 35(1):29- 33.

[14]. Natsis K, Totlis T, Tsikaras P, Appell HJ, Skandalakis $\mathrm{P}$, Koebke J. Proposal for classification of the suprascapular notch : a study on 423 dried scapulas. Clin Anat 2007;20(2):135-9.

[15]. Sangam MR, Sarda Devi SS, Krupadanam K, Anasuya K. A Study on the morphology of the suprascapular notch and its distance from the glenoid cavity. J Clin Diagn Res. 2013; 7: 189-92.

[16]. Wang HJ, Chen C, Wu LP, Pan CQ, Zhang WJ, Li YK. Variable Morphology of the Suprascapular Notch: An investigation and Quantitative Measurements in Chinese Population. Clin. Anat. 2011; 24:47-55.

[17]. Apurba Patra, Manjeet Singh, Harsimarjit Kaur. Variations in the Shape and Dimension of the Suprascapular Notch in Dried Human Scapula-An Osteological Study with its Clinical Implications. International Journal of Anatomy, Radiology and Surgery, 2016;5(2) 1-5. 